\title{
Alternative Synthetic Method and Antimicrobial Activity Screening of Co (II) and Cu (II) Complexes of 2-(Acetyloxy) Benzoic Acid (Aspirin)
}

\author{
Isah Jibrin $^{1 *}$, Kurawa, M. A ${ }^{2}$, Mohammed, $\mathbf{J}^{1}$., Stephen I. Audu ${ }^{1}$, Mohammed, $\mathbf{J}^{1}$ and Bathiya, S. S. ${ }^{1}$ \\ ${ }^{1}$ Department of Chemistry, Nasarawa State University, Keffi, Nigeria, ${ }^{2}$ Department of Chemistry, Bayero University, Kano, \\ Nigeria
}

\begin{abstract}
Mechanochemical synthesis of $\mathrm{Co}$ (II) and $\mathrm{Cu}$ (II) aspirin complexes was carried out by simple grinding of metal (II) acetates with aspirin without any solvent. Also conventional preparation of the above complexes was carried out for comparison purposes using the solution-based method. The products of mechanochemical synthesis were characterized by comparison of solubility, melting points, conductivity values, magnetic moment and IR analyses with those of ligands and conventional solution-based products. The IR spectral and analytical data of the complexes were similar for both products of the two synthetic routes suggesting the formation of identical compounds. Job's method analyses suggested 1:2 metal to ligand ratio. The elemental analyses results revealed identical percentage composition of each element found in the products as compared to those of calculated percentages. The complexes have low values of molar conductance $\left(4.24-6.60 \Omega^{-1} \mathrm{~cm}^{2} \mathrm{~mol}^{-1}\right)$ implying that they are non-electrolytes in DMSO. The complexes were all soluble in dimethylformamide and dimethylsulfoxide. The complexes were mostly soluble in non-polar solvents. All the products decomposed at a temperature range of $177.0-181.9^{\circ} \mathrm{C}$ higher than that of their ligand revealing their more stable nature. The magnetic moment values obtained proved the paramagnetic nature of the synthesized complexes. The products and the ligand were screened against three bacteria isolates; Escherichia coli, Kledsiella pneumonia, Staphylococcus aureus and two fungi isolates; Aspergillus fumigatus, Mucus specie for antimicrobial activity. The results shows that the ligand was inactive against all the test organisms; the complexes were active in all test concentration, with only $\mathrm{Co}(\text { asp })_{2}$ complex inactive against Staphylococcus Aureus at a concentration of $15 \mu \mathrm{g} / \mathrm{disc}$.
\end{abstract}

Keywords:- Mechanochemical, Ligand, Complex, Job's Method, Antimicrobial, Aspirin.

\section{INTRODUCTION}

Innovation involving developing an alternative synthetic route for the syntheses of chemical substances without the use of solvent is an attractive goal in the chemical world. This will of course allow chemist and chemical industries to carry out reactions more efficiently, with less waste, less cost and without using volatile, flammable or toxic solvents. In Solvent-based synthesis, solvent allows the reactant molecules to mix together closely so that they can interact to form a product. Without solvent, the same reactions can sometimes be brought about by grinding the reactants in solid states together manually by using mortar and pestle or using ball mill and this has been used as a solvent free synthetic method for the production of different metal complexes [5]; [20]; [4]; [21].

Mechanochemistry is a branch of chemistry concerned with the transformations of chemical substances in all state of aggregation induced by mechanical energy [9].

Aspirin is derived from salicylic acid which is also referred as to acetyl salicylic acid or 2-(acetyloxy) benzoic acid. It is used as analgesic and antipyretic agent and is also used as NSAID. It has also anti-blood clotting effect which is used in long term at low doses to prevent heart attack and stroke [12].

Reference [14] reported the synthesis of aspirin and paracetamol complexes with $\mathrm{Co}(\mathrm{II}), \mathrm{Ni}(\mathrm{II})$ and $\mathrm{Fe}(\mathrm{III})$ and Reference [17] reported the synthesis of $\mathrm{Mn}(\mathrm{II}), \mathrm{Co}(\mathrm{II})$, $\mathrm{Fe}(\mathrm{II})$ and $\mathrm{Cu}(\mathrm{II})$ paracetamol and ibuprofen complexes all via conventional solution-based synthetic route involving refluxing with ethanol for 3 hours as this is time consuming, requires more heat, solvent usage, use of more sophisticated equipment which are sometimes delicate to handle and expensive to buy.

Many drugs and other pharmaceutical agents has metal-binding sites which enable them to act as potential ligands. And this will allow them bind or coordinate with metal ions which potentially influence their bioactivities [17]. Coordination compounds are however gaining interest globally in drug design as drugs are used to coordinate with metals to form complex compounds and this has led to lots of study on metal-drug complexes [14].

It was therefore thought that a new synthetic approach should be employed in the synthesis of these metal-drug complexes which are known for their chemotherapeutic properties. This research work hereby reports mechanochemical synthesis, characterization and antimicrobial screening of metal (II) complexes of active pharmaceutical ingredient, aspirin on comparison with complexes synthesized via solution-based synthesis. 


\section{RESEARCH METHODOLOGY}

Analytical grade chemicals were used in the process without any further purification throughout. The active pharmaceutical ingredients, aspirin powder was obtained from Dana Pharmaceutical Company, Minna, Nigeria. Metal salts used include Cobalt acetate and copper acetate.

All the glass wares used were washed thoroughly with detergent, rinsed with distilled water and dried in an oven at $110^{\circ} \mathrm{C}$. All weighing was carried out using College Weighing balance of model B154 METTLER TOLEDO. Molar conductance measurement was done using Jenway conductivity meter of model 4010 in DMSO and Jenway 6305 UV-Visible Spectrophotometer was used for UVabsorbance measurement. Decomposition/melting temperature were recorded using Gallenkamp melting apparatus. Magnetic susceptibility measurement of the complexes was recorded using magnetic susceptibility balance of model MK 1 Sharwood. The bacteria and fungi isolates (bacteria; Escherichia coli, Kledsiella pneumonia, Staphylococcus aureus and fungi isolates; Aspergillus fumigatus, Mucus specie) were obtained and identified at Department of Microbiology, Bayero University Kano. Infrared spectra of the ligand and the complexes were recorded using Fourier Transform Infrared Spectrophotometer of model Shimadzu FTIR 8400S with the band range of 380 to $4000 \mathrm{~cm}^{-1}$. Elemental analyzer of model Eager 300 was used to obtain the elemental analytical data of the synthesized complexes. Assay for purity of the ligand was carried out using High Performance Liquid Chromatography, HPLC Agilent Technologies of model 1260Infinity at the instrument laboratory, Department of Pure and Industrial Chemistry, Bayero University Kano.

\section{Synthesis of the Complex}

\section{- Mechanochemical Synthesis of Cobalt (II) aspirin Complex}

$3.603 \mathrm{~g}(0.02 \mathrm{~mol})$ of aspirin and $2.491 \mathrm{~g}(0.01 \mathrm{~mol})$ of $\mathrm{Co}\left(\mathrm{CH}_{3} \mathrm{COO}\right)_{2} .4 \mathrm{H}_{2} \mathrm{O}$ were ground in an agate mortar to obtain fine powder as product accompanied with the release of characteristic odour of acetic acid. The product was then dried in desiccator as complex.

\section{- Solution Synthesis of Cobalt (II) aspirin Complex} An aqueous solution of hydrated salt, $\mathrm{Co}\left(\mathrm{CH}_{3} \mathrm{COO}\right)_{2} .4 \mathrm{H}_{2} \mathrm{O}(2.491 \mathrm{~g}, 0.01 \mathrm{~mol})$ in $10 \mathrm{~cm}^{3}$ ethanol was added to an ethanolic solution of aspirin $(3.603 \mathrm{~g}$, $0.02 \mathrm{~mol})$, the mixture was refluxed for 3 hours with constant stirring. The green precipitated complex formed was separated by filtration, washed with ethanol and dried in desiccator over phosphorus (v) oxide for 24hours.
- Mechanochemical Synthesis of Copper (II) aspirin Complex

$3.603 \mathrm{~g}(0.02 \mathrm{~mol})$ of aspirin and $1.997 \mathrm{~g}(0.01 \mathrm{~mol})$ of $\mathrm{Cu}\left(\mathrm{CH}_{3} \mathrm{COO}\right)_{2} \cdot \mathrm{H}_{2} \mathrm{O}$ were ground in an agate mortar to obtain fine powder as product accompanied with the release of characteristic odour of acetic acid. The product was then dried in desiccator as complex.

\section{- Solution Synthesis of Copper (II) aspirin Complex}

An aqueous solution of hydrated salt, $\mathrm{Cu}\left(\mathrm{CH}_{3} \mathrm{COO}\right)_{2} .2 \mathrm{H}_{2} \mathrm{O}(1.997 \mathrm{~g}, 0.01 \mathrm{~mol})$ in $10 \mathrm{~cm}^{3}$ ethanol was added to an ethanolic solution of aspirin $(3.603 \mathrm{~g}$, $0.02 \mathrm{~mol})$, the mixture was refluxed for 3hours with constant stirring. The pale blue precipitated complex formed was separated by filtration, washed with ethanol and dried in desiccator over phosphorus (V) oxide for 24hours.

\section{- Determination of Metal to Ligand Ratio}

Job's method of continuous variation was used to determine the number of the ligand coordinated to the metal ion.

3 mmolar solutions of the ligands and metal salts were prepared. The following metal to ligand ratio (in $\mathrm{ml}$ ); 0:16, $1: 15,3: 13,5: 11,7: 9,9: 7,11: 5,13: 3,15: 1$ were measured from the ligand solution and each of the metal salt solutions respectively. In that order, a total volume of $16 \mathrm{ml}$ was maintained throughout the process. The ligand mole fraction was calculated in each mixture. The wavelength of maximum absorption $\left(\lambda_{\max }\right)$ for a particular metal ion was determined after scanning (as blank) the solution of that metal salt. The machine was fixed at $\lambda_{\max }$ (in each case) before taking the absorbance values.

The number of coordinated ligand (coordination number) was determined using the equation below by extrapolating absorbance values against mole fraction of the ligand.

$$
\bar{n}=\frac{X i}{(1-X i)}
$$

Where $\mathrm{n}=$ number of coordinated ligand and $\mathrm{x}_{\mathrm{i}}=$ mole fraction at maximum absorbance

\section{> Antibacterial Activity Test}

Various test concentrations were prepared in accordance with the dilution method described by reference [22]. A stock solution of the ligand and the metal(II) complexes were prepared by dissolving $0.06 \mathrm{~g}$ of the ligand or their metal complexes in $1 \mathrm{~cm}^{3}$ of DMSO. The stock solution contains $60 \mu \mathrm{g}$ per $\mathrm{cm}^{3}$ of DMSO. 30 $\mathrm{gg}$ was prepared from the stock solution by taken $0.5 \mathrm{~cm}^{3}$ of the stock and added $0.5 \mathrm{~cm}^{3}$ of the DMSO. Subsequently $15 \mu \mathrm{g}$ was prepared by taken $0.5 \mathrm{~cm}^{3}$ of $30 \mu \mathrm{g}$ and added $0.5 \mathrm{~cm}^{3}$ into another bottle. These bottles containing the various concentrations were impregnated with 50pcs of paper disc. The paper discs were used to inoculate the culture plate. The culture media (nutrient agar) was incubated at $37^{\circ} \mathrm{c}$ for $24 \mathrm{hrs}$ and the evaluation of the antibacterial activity of the 
ligands, their complexes observed and the diameter of zones of inhibition recorded.

\section{Antifungal Activity}

Various test concentrations were prepared in accordance with the dilution method described by reference [8]. A stock solution of the ligand and the metal (II) complexes were prepared by dissolving $0.06 \mathrm{~g}$ of the ligand or their metal complexes in $1 \mathrm{~cm}^{3}$ of DMSO. The stock

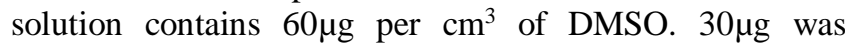
prepared from the stock solution by taking $0.5 \mathrm{~cm}^{3}$ of the stock and added $0.5 \mathrm{~cm}^{3}$ of the DMSO. Furthermore, $15 \mu \mathrm{g}$ was prepared by taking $0.5 \mathrm{~cm}^{3}$ of $30 \mu \mathrm{g}$ and added $0.5 \mathrm{~cm}^{3}$ into another bottle. These bottles containing the various concentrations were impregnated with 50pcs of paper disc. The paper discs were used to inoculate the culture plate. The culture media (sabouraud dextrose agar) was incubated at room temperature for $48 \mathrm{hrs}$ and the paper disc technique was used to evaluate the antifungal activity of the ligands, their complexes and the diameter of zones of inhibition recorded after $72 \mathrm{hrs}$.

\section{RESULTS AND DISCUSSION}

Reactions were achieved via mechanochemical means and completed within a shorter time of 15 minutes as compared to solution-based method which took hours to obtain the product. The products were generally obtained with neither waste nor further purification processes.
The results of the analysis of the ligand and their metal (II) complexes are presented in table 1 to 7 and figure 1 to 2 below:

\section{Percentage Yield and Colour}

The analytical data of the complexes of aspirin prepared via the two different methods presented in table 1 below are similar with exception in their percentage yield. The interaction of aspirin and the metal salts yielded coloured complexes which of course may be due to the electron transition from metal to the ligand and vice-versa. $\mathrm{Co}(\mathrm{II})$ and $\mathrm{Cu}(\mathrm{II})$ aspirin complexes prepared mechanochemically are army green and pale blue respectively, while solution-based products are dirty green and turquoise. Mechanochemical products are of very good yield that ranges from $97.60 \%$ to $99.50 \%$ higher than those synthesized via solution method which ranges from $59.13 \%$ to $75.08 \%$.

\section{$>$ Decomposition Temperature}

Aspirin melted at a temperature of $137^{\circ} \mathrm{C}$ whereas its interaction with respective metal (II) ions yielded complexes with decomposition temperature of $181.0^{\circ} \mathrm{C}\left(177.30^{\circ} \mathrm{C}\right)$ and $181.9^{\circ} \mathrm{C}\left(179.0^{\circ} \mathrm{C}\right)$ for $\mathrm{Co}(\mathrm{II})$ and $\mathrm{Cu}(\mathrm{II})$ aspirin complexes synthesized via mechanochemical and solution-based method respectively. This higher values than that of the free aspirin provide evidence of coordination of the ligand to the respective metal ions and also revealed the more stable nature of the complexes as shown in Table 1.

\begin{tabular}{|c|c|c|c|c|c|}
\hline Compounds & Method & \% Yield & Colour & $\begin{array}{c}\text { Melting } \\
\text { temperature }\left({ }^{\circ} \mathrm{C}\right)\end{array}$ & $\begin{array}{c}\text { Decomposition } \\
\text { temperature }\left({ }^{\circ} \mathrm{C}\right)\end{array}$ \\
\hline Aspirin & & & White & 137 & - \\
$\mathrm{Co}(\mathrm{Asp})_{2}$ & Mechanochemical & 97.60 & Army green & - & 181.0 \\
$\mathrm{Co}($ Asp) 2 & Solution-based & 59.59 & Dark green & - & 177.3 \\
$\mathrm{Cu}($ Asp) 2 & Mechanochemical & 99.52 & Pale Blue & - & 181.9 \\
$\mathrm{Cu}($ Asp) 2 & Solution-based & 75.08 & Turquoise & - & 179.0 \\
& & & & & \\
\end{tabular}

Table 1:- Physical Properties of Aspirin and its Metal (II) Complexes Synthesized by both Methods

\section{Solubility}

Aspirin is soluble in methanol, DMF and DMSO whereas it complexes were all insoluble in ethanol and water, all soluble in DMF, DMSO, while others were soluble in some organic solvents and slightly soluble in other organic solvents as shown in table 2 below. 
ISSN No:-2456-2165

\begin{tabular}{|c|c|c|c|c|c|c|c|c|c|c|}
\hline $\begin{array}{c}\text { Ligand/ } \\
\text { Complexes }\end{array}$ & Method & $\begin{array}{c}\text { Distilled } \\
\text { water }\end{array}$ & Methanol & Ethanol & Acetone & chloroform & DEE & Pet. Ether & DMF & DMSO \\
\hline Aspirin & & IS & S & SS & IS & IS & SS & IS & S & S \\
$\mathrm{Co}(\text { Asp })_{2}$ & Mechano & IS & S & IS & SS & SS & S & SS & S & S \\
$\mathrm{Co}(\text { Asp })_{2}$ & Solution & IS & S & IS & SS & SS & S & SS & S & S \\
$\mathrm{Cu}(\text { Asp })_{2}$ & Mechano & IS & SS & IS & S & S & SS & S & S & S \\
$\mathrm{Cu}(\text { Asp })_{2}$ & Solution & IS & SS & IS & S & S & SS & S & S & S \\
\hline
\end{tabular}

Key: S-soluble, SS-slightly soluble, IS-insoluble

Table 2:- Solubility of Aspirin and its Metal (II) Complexes Synthesized by both Methods

\section{Magnetic Properties}

The results of the magnetic properties of aspirin complexes are presented in table 3 . The values of the magnetic susceptibility obtained revealed that all the complexes are paramagnetic. Paramagnetic property is due to presence of unpaired electrons in the partially filled dorbital of the central metal ion [15].

The suggestion of the likely geometry of complexes can also be provided by their magnetic moment. The results of the observed effective magnetic moment measured at room temperature for aspirin metal (II) complexes are presented in Table 3. The values of the effective magnetic moment were similar for both complexes from the two different synthetic routes. The values ranges from 4.27BM4.88BM and 1.85BM-1.96BM for $\mathrm{Co}(\mathrm{II})$ and $\mathrm{Cu}$ (II) aspirin complexes.

The values 4.27BM and 4.88BM obtained for Co(II) aspirin complexes tentatively proposes high spin octahedral geometry since the values lies within the range that correspond to spin-only value magnetic moment (3.875.2BM) for high spin octahedral geometry around $\mathrm{Co}(\mathrm{II})$ ions. This is in agreement with the research conducted by reference [2].

The values 1.85BM and 1.96BM for mechanochemical and solution-based $\mathrm{Cu}(\mathrm{II})$ aspirin complexes tentatively proposes distorted octahedral geometry. This is in agreement with the research conducted by reference [7]. Though, it was reported also that this values lies within the expected range for square pyramidal too [6].

The $\mu_{\text {eff }}$ values which are higher or lower than spinonly values for the respective metal (II) ion concerned may be due to spin-orbit coupling.

The observed $\mu_{\text {eff }}$ for $\mathrm{Co}(\mathrm{II})$ chelate at room temperature are 4.39BM and 4.10BM for mechanochemical and solution products which lies within expected range for high-spin octahedral $\mathrm{Co}$ (II) complexes, though slightly higher than value corresponding to spin-only magnetic moment, 3.87BM for octahedral Co(II) complexes obtained may be due to orbital contribution [7].

\section{Molar Conductivity}

The molar conductance of metal (II) aspirin complexes measured at room temperature in $1 \times 10^{-3} \mathrm{M}$ DMSO are presented in table 3. The molar conductance values for both mechanochemical and solution-based synthesized products are low and quite similar. Co(II), $\mathrm{Cu}$ (II) aspirin complexes has molar conductance values of 5.21 $\left(4.89 \Omega^{-1} \mathrm{~cm}^{2} \mathrm{~mol}^{-1}\right), \quad 4.58\left(4.55 \Omega^{-1} \mathrm{~cm}^{2} \mathrm{~mol}^{-1}\right), \quad$ for mechanochemical and solution-based products respectively. The range, $4.24-6.60 \Omega^{-1} \mathrm{~cm}^{2} \mathrm{~mol}^{-1}$ is low within the expected values indicating that the complexes are nonelectrolytes in DMSO.This is in agreement with the research conducted by reference [19]; [16]; [18].

\begin{tabular}{|c|c|c|c|c|c|}
\hline Complex & Method & $\begin{array}{c}\text { Magnetic } \\
\text { susceptibility }(\mathbf{X g}) \\
\left(\mathrm{g}^{-1}\right)\end{array}$ & $\begin{array}{c}\mathbf{X m} \\
\left(\mathrm{mol}^{-1}\right)\end{array}$ & $\begin{array}{c}\text { Effective } \\
\text { magnetic } \\
\text { moment }_{(\mathrm{BM})}\end{array}$ & $\begin{array}{c}\text { Molar } \\
\text { conductivity } \\
\left(\Omega^{-1} \mathrm{~cm}^{2} \mathrm{~mol}^{-1}\right)\end{array}$ \\
\hline $\mathrm{Co}(\mathrm{Asp})_{2}$ & Mechanochemical & $1.835 \times 10^{-5}$ & $7.656 \times 10^{-3}$ & 4.27 & 5.20 \\
$\mathrm{Co}(\mathrm{Asp})_{2}$ & Solution-based & $2.403 \times 10^{-5}$ & $1.003 \times 10^{-2}$ & 4.88 & 4.89 \\
$\mathrm{Cu}(\mathrm{Asp})_{2}$ & Mechanochemical & $3.409 \times 10^{-6}$ & $1.438 \times 10^{-3}$ & 1.85 & \\
$\mathrm{Cu}(\mathrm{Asp})_{2}$ & Solution-based & $3.858 \times 10^{-6}$ & $1.627 \times 10^{-3}$ & 1.96 & 4.55 \\
\hline
\end{tabular}

Table 3:- Effective Magnetic Moment and Molar Conductance of Metal (II) Aspirin Complexes 


\section{IR Analysis}

The results of the IR analysis are presented in table 4. The broad absorption band at $3003.27 \mathrm{~cm}^{-1}$ in the spectrum of free aspirin has been attributed to $\mathrm{O}-\mathrm{H}$ vibration frequency of the carboxylic group. This band disappeared in the spectra of the complexes due to coordination through the oxygen of the $\mathrm{O}-\mathrm{H}$ of carboxylic group with deprotonation, as observed in both products of mechanochemical and solution-based synthesis respectively. The bands at $1755.28 \mathrm{~cm}^{-1}$ and $1686.81 \mathrm{~cm}^{-1}$ in the spectrum of free aspirin are assigned to $\mathrm{v}(\mathrm{C}=\mathrm{O})$ of ester and carboxylic acid respectively, as these bands shifted to different frequencies, $1751.28 \mathrm{~cm}^{-1}\left(1752.42 \mathrm{~cm}^{-1}\right)$ and $1679.09 \mathrm{~cm}^{-1}\left(1627.01 \mathrm{~cm}^{-1}\right), 1750.46 \mathrm{~cm}^{-1}\left(1751.42 \mathrm{~cm}^{-1}\right)$ and $1684.88 \mathrm{~cm}^{-1}\left(1670.09 \mathrm{~cm}^{-1}\right)$, for $\mathrm{Co}(\mathrm{Asp})_{2}$ and $\mathrm{Cu}(\mathrm{Asp})_{2}$ complexes respectively. This shifting also provides evidence that these groups are also coordination sites of aspirin. The bands at $1298.14 \mathrm{~cm}^{-1}$ and $1015.56 \mathrm{~cm}^{-1}$ in free aspirin are attributed to $\mathrm{C}-\mathrm{O}$ stretching vibrations of carboxylic and ester groups, as these bands shifted to higher and lower frequencies, $1301.99 \mathrm{~cm}^{-1}\left(1303.92 \mathrm{~cm}^{-1}\right)$ and $1030.02 \mathrm{~cm}^{-1}\left(1034.84 \mathrm{~cm}^{-1}\right), 1299.10 \mathrm{~cm}^{-1}\left(1301.99 \mathrm{~cm}^{-1}\right)$ and $1024.24 \mathrm{~cm}^{-1}\left(1030.02 \mathrm{~cm}^{-1}\right)$, in both mechanochemical and solution aspirin complexes respectively. This supports the formation of new compounds. The similar bands at a range $655.82 \mathrm{~cm}^{-1}$ to $688.82 \mathrm{~cm}^{-1}$ in the spectra of mechanochemical and solution products of $\mathrm{Co}$ (II) and $\mathrm{Cu}$ (II) aspirin complexes which could not be exactly traced in the spectrum of free aspirin have been tentatively assigned to (M-O) stretching frequencies, supporting coordination of aspirin to respective metal ions.

\begin{tabular}{|c|c|c|c|c|c|c|}
\hline $\begin{array}{l}\text { Ligand/ } \\
\text { complex }\end{array}$ & Method & $\begin{array}{l}v(\mathrm{O}-\mathrm{H}) \mathrm{cm}^{-1} \\
\text { of carboxy- } \\
\text { lic acid }\end{array}$ & $\begin{array}{c}v(\mathrm{C}=\mathrm{O}) \mathrm{cm}^{-1} \text { of ester/ } \\
v(\mathrm{C}=\mathrm{O}) \mathrm{cm}^{-1} \text { of } \\
\text { carboxylic acid }\end{array}$ & $\begin{array}{l}\text { C-O str. of } \\
\text { Carboxylic } \\
\quad \text { acid }\end{array}$ & $\begin{array}{c}\text { C-O str. Of } \\
\text { ester }\end{array}$ & $\begin{array}{c}\mathrm{M}-\mathrm{O} \text { and } \\
\mathrm{M}-\mathrm{O}=\mathrm{C}\end{array}$ \\
\hline Aspirin & & 3003.27 & $1755.28, \quad 1686.81$ & 1298.14 & 1015.56 & - \\
\hline $\mathrm{Co}(\mathrm{Asp})_{2}$ & Mechanochemical & - & $1751.42, \quad 1679.09$ & 1301.99 & 1030.02 & 655.82 \\
\hline $\mathrm{Co}(\mathrm{Asp})_{2}$ & Solution-based & - & $1752.42, \quad 1627.01$ & 1303.92 & 1034.84 & 658.71 \\
\hline $\mathrm{Cu}(\mathrm{Asp})_{2}$ & Mechanochemical & - & $1750.46, \quad 1684.88$ & 1299.10 & 1024.24 & 680.89 \\
\hline $\mathrm{Cu}(\mathrm{Asp})_{2}$ & Solution-based & - & $1751.42, \quad 1670.09$ & 1301.99 & 1030.02 & 688.82 \\
\hline
\end{tabular}

Table 4:- The IR Spectra Data of Aspirin and its Metal (II) Complexes

\section{$>$ Elemental Analysis}

The elemental analytical data revealed the percentage of carbon, hydrogen and oxygen to be $8.97 \%, 42.08 \%$ and $1.88 \%$ respectively, while the theoretical/ calculated percentage was found to be $9.64 \%, 41.33 \%$ and $2.77 \%$ for carbon, hydrogen and oxygen revealing similar percentage composition of the elements present in both reactants and products as presented in the table below;

\begin{tabular}{|c|c|c|c|c|}
\hline Complex & & Percentage (\%) & & \\
& Element: & Carbon & Hydrogen & Oxygen \\
\hline $\mathrm{Cu}(\mathrm{Asp})_{2}$ & Calculated: & 51.04 & 3.77 & 30.20 \\
& Found: & 49.09 & 2.88 & 30.49 \\
& & & & \\
$\mathrm{Co}(\mathrm{Asp})_{2}$ & Calculated: & 51.52 & 3.82 & 30.53 \\
& Found: & 50.32 & 2.78 & 29.99 \\
\hline
\end{tabular}

Table 5:- Elemental Analytical Data of the Metal (II) Complexes

\section{$>$ Biological Activity}

Antimicrobial screening results as shown in table 6 and 7 below revealed that the ligands are inactive towards inhibiting the growth of the bacteria and fungi in all concentrations. Copper complex showed activity against all the isolates in all concentrations except and $\mathrm{Co}(\mathrm{asp})_{2}$ complex which was inactive at $15 \mu \mathrm{g} / \mathrm{disc}$ against Staphylococcus Aureus and inactive against Aspergillus fumigatus at all concentrations. $\mathrm{Cu}(\mathrm{asp})_{2}$ showed highest activity against Mucus specie. In general, these results revealed that the synthesized complexes have significant antibacterial and antifungal strength even at low concentration of $60 \mu \mathrm{g} / \mathrm{disc}$. However, this inhibitory action increases with increase in concentration of the complexes. 
ISSN No:-2456-2165

\begin{tabular}{|c|c|c|c|c|c|}
\hline \multirow[t]{2}{*}{ Test Organism } & \multirow[t]{2}{*}{ Ligand/Complex } & \multicolumn{3}{|c|}{$\begin{array}{l}\text { Inhibition Zone }(\mathrm{mm}) \text { at different } \\
\text { Concentration }(\mu \mathrm{g} / \mathrm{disc})\end{array}$} & \multirow[t]{2}{*}{$\begin{array}{c}\text { Control disk } \\
\text { Ampiclox }(10 \mu \mathrm{g} / \mathrm{disc})\end{array}$} \\
\hline & & 15 & 30 & 60 & \\
\hline $\begin{array}{l}\text { Escherichia } \\
\text { coli }\end{array}$ & $\begin{array}{c}\text { Aspirin } \\
\mathrm{Co}(\text { Asp })_{2} \\
\mathrm{Cu}(\text { Asp })_{2}\end{array}$ & $\begin{array}{l}\text { NZI } \\
8 \\
9\end{array}$ & $\begin{array}{l}\text { NZI } \\
9 \\
11\end{array}$ & $\begin{array}{r}\text { NZI } \\
11 \\
14\end{array}$ & 31 \\
\hline $\begin{array}{l}\text { Klebsiella } \\
\text { Pneumonia }\end{array}$ & $\begin{array}{c}\text { Aspirin } \\
\mathrm{Co}(\text { Asp })_{2} \\
\mathrm{Cu}(\text { Asp })_{2}\end{array}$ & $\begin{array}{c}\text { NZI } \\
13 \\
9\end{array}$ & $\begin{array}{c}\text { NZI } \\
16 \\
11\end{array}$ & $\begin{array}{c}\text { NZI } \\
18 \\
14\end{array}$ & 22 \\
\hline $\begin{array}{l}\text { Staphylococcus } \\
\text { Aureus }\end{array}$ & $\begin{array}{c}\text { Aspirin } \\
\mathrm{Co}(\mathrm{Asp})_{2} \\
\mathrm{Cu}(\mathrm{Asp})_{2}\end{array}$ & $\begin{array}{l}\text { NZI } \\
\text { NZI } \\
9\end{array}$ & $\begin{array}{l}\text { NZI } \\
9 \\
12\end{array}$ & $\begin{array}{r}\text { NZI } \\
11 \\
14\end{array}$ & 25 \\
\hline
\end{tabular}

Key: NZI = No Zones of Inhibition

Table 6:- Antibacterial Activity of Aspirin and their Metal (II) Complexes

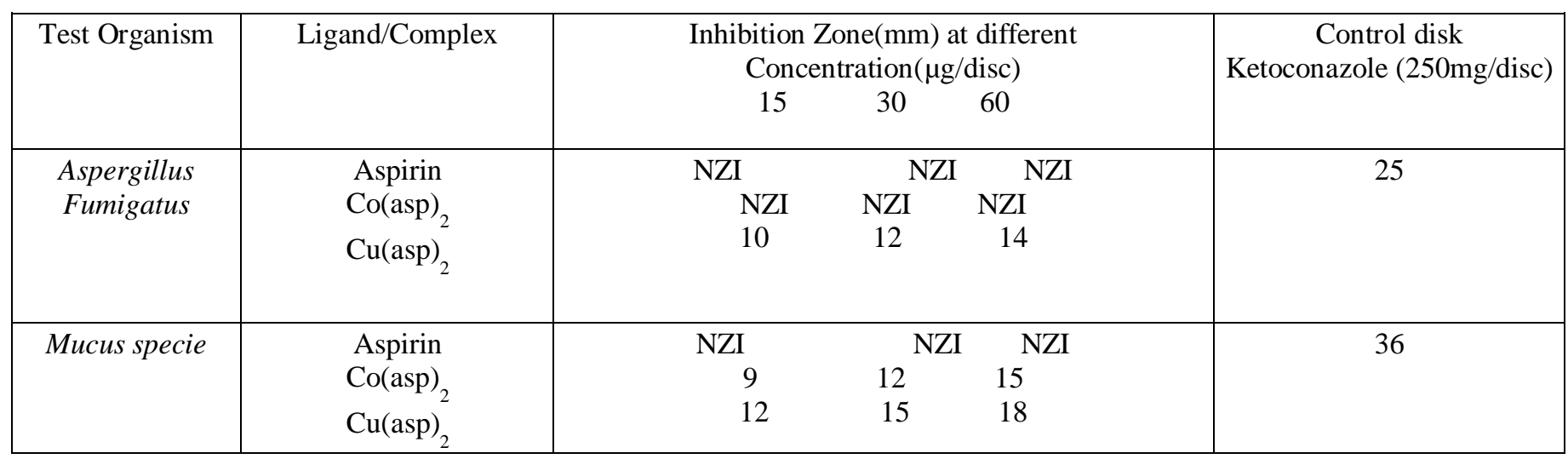

Key: NZI = No Zones of Inhibition

Table 7:- Antifungal Activity of Aspirin and their Metal (II) Complexes

\section{Job's Method}

The number of ligand coordinated to the metal in the two complexes synthesized, $\bar{n}$ was calculated to be 2 using equation (1) above. This however, suggested 1:2 metal to ligand ratio.

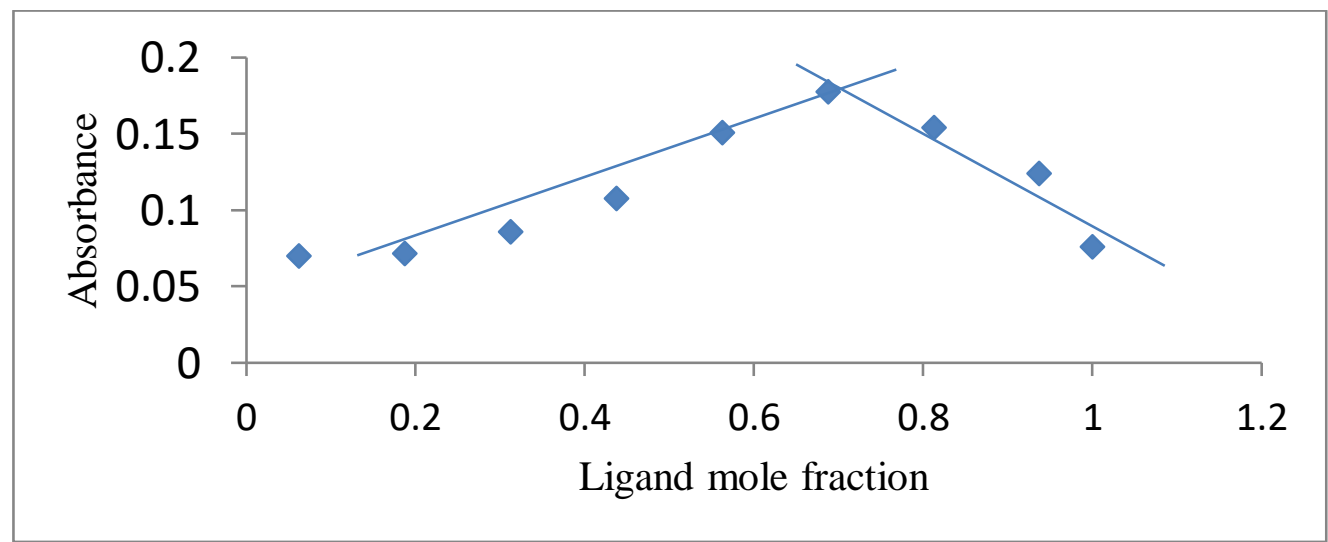

Fig 1:- Plot of absorbance against ligand (Aspirin) mole fraction for Co(II) acetate 
ISSN No:-2456-2165

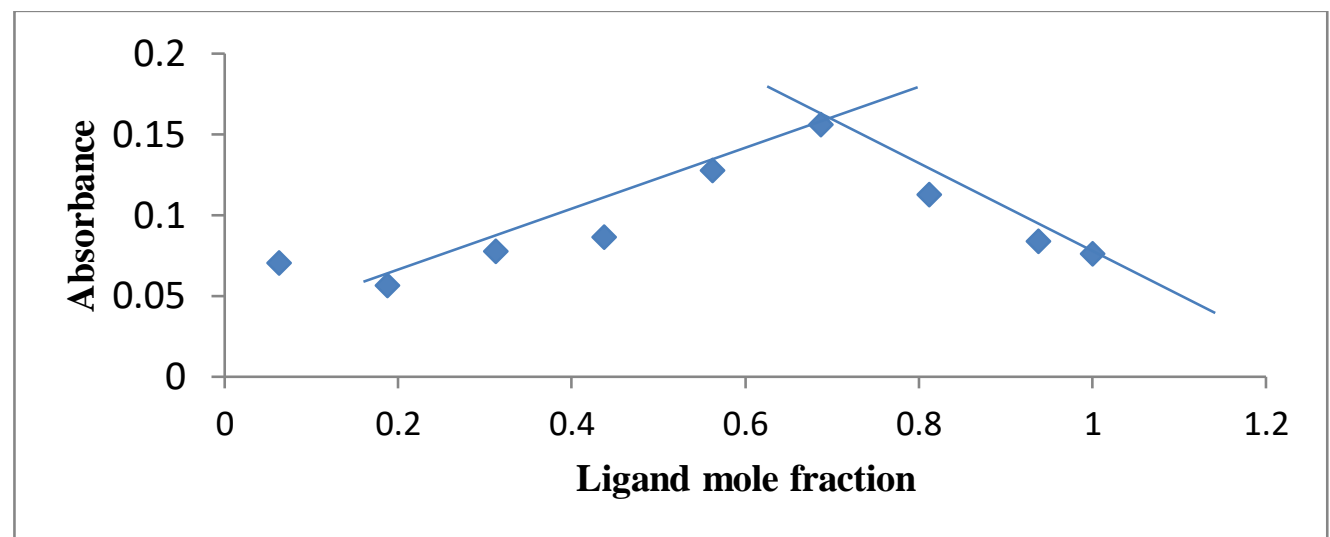

Fig 2:- Plot of absorbance against ligand (Aspirin) mole fraction for $\mathrm{Cu}(\mathrm{II})$ acetate

On the basis of the analytical data obtained viz: melting point, conductivity measurement, magnetic susceptibility(effective magnetic moment), Job's method, elemental analysis and FTIR spectroscopic studies, the structures tentatively proposed for the metal (II) complexes are as follows:-

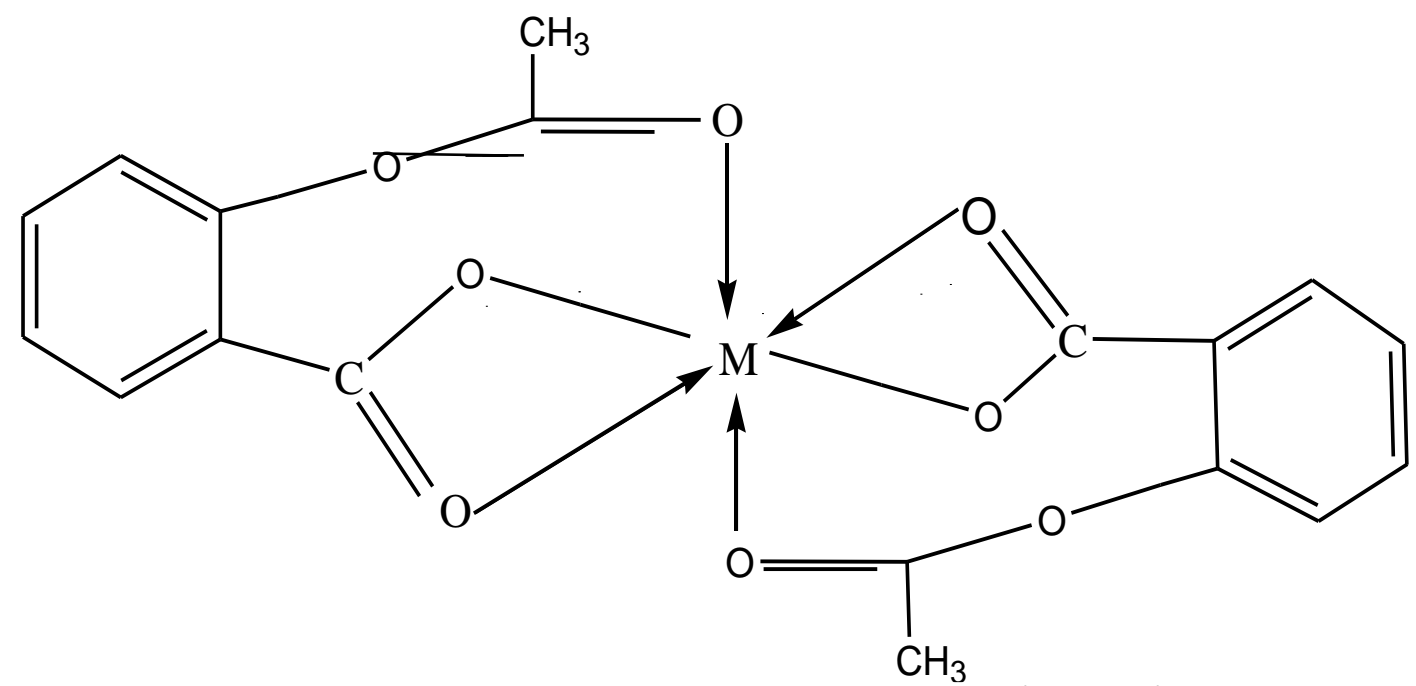

Fig 3:- Proposed structure of aspirin complexes $\left(\mathrm{M}=\mathrm{Co}^{2+}\right.$ and $\left.\mathrm{Cu}^{2+}\right)$

\section{CONCLUSION}

This research work has demonstrated the use of mechanochemical synthetic approach for the synthesis of metal (II) complexes of aspirin. It was found out that the solvent free solid-solid state reaction can be used to obtain the same product as that obtained from conventional method. For all complexes, the obtained IR data and effective magnetic moment values suggested the geometry and coordination of molecules of aspirin to their respective metal ions. Aspirin coordinate through carbonyl oxygen of both carboxylic and ester group and also through oxygen of the $\mathrm{O}-\mathrm{H}$ of carboxylic group after deprotonation giving rise to octahedral geometry. The bands at different frequencies that appeared, shifted and disappeared in the IR spectra of the resulting products in both cases of solvent free technique and solution-based syntheses were similar. Therefore, it can be concluded that structures of the products synthesized mechanochemically are comparable to those obtained via solution syntheses. In contrast to complexes from solution method, mechanochemical products gave high yield, do not require any purification procedure, eco-friendly, low cost, fast, complete solid-solid conversion between metal salts and ligand, stoichiometric and low temperature solid state synthesis, providing possible access to different types of coordination compounds formation. Mechanochemical synthesis, therefore, is the best alternative synthetic route to obtain complexes over conventional method.

\section{REFERENCES}

[1]. A. M. Algra, P. M. Rothwell, and L.Oncol, "Effect of Regular Aspirin on Long-term Cancer Incidence and Metastasis: A Systematic Comparason of Evidence from Observational Studies Versus Randomised Trials" 13(5): 2012, pp. 518-527

[2]. T.H. Al- Noor, F.H. Ghanim and A.S. Kindeel, "Synthesis, characterization and antibacterial activity of $\mathrm{Mn}$ (II), $\mathrm{Fe}(\mathrm{II}), \mathrm{Ni}(\mathrm{II}), \mathrm{Cu}(\mathrm{II}), \mathrm{Zn}(\mathrm{II}), \mathrm{Cd}(\mathrm{II})$ and $\mathrm{Hg}$ (II) Mixed- Ligand complexes containing fural-2-carboxylic acid and (1,10-Phenanthroline)", Advances in Physics Theory and Applications. Vol. 29. 2014, pp.1-7 
[3]. R. J. Angelici, "Synthesis and techniques in inorganic chemistry", W.B Savders Company, $2^{\text {nd }}$ ed., 1971, pp. 115-125.

[4]. G. A. Bowmaker, "et al. "Mechanochemical synthesis in copper (II) halide/pyridine systems: single crystal X-ray diffraction and IR spectroscopic studies", Dalton Trans, Roy. Soc. Chem., 40 (27), pp. 72107218, 2011

[5]. D. Braga, F. Grespion, L. Maini, R. Brescello and L. Catairea, "Simple and qualitative mechanochemical preparation of the first zinc and copper complexes of the neuroleptic drug gabapentin" Cryst. Eng. Comm, 10 (5), Roy. Soc. Chem., pp. 469-471, 2008

[6]. B. Cristovoa, "Spectral, thermal and magnetic properties of $\mathrm{Cu}$ (II) and $\mathrm{Ni}$ (II) complexes with schiff base ligands", J. Serb. Chem. Soc. 76 (12), 1639-1648, 2011

[7]. R.A. El-Halawa, "et al., "Synthesis, characterization and antifungal activity of some metal complexes derived from quinoxaloylhydrazone". World Journal of Organic Chemistry, Vol. 3(1), pp.1-8, 2015

[8]. S. W. Hassan, R. A. Umar, M. Lawal, L. S. Bilbis and B. Y. Muhammed, "Evaluation of antifungal activity of Ficus sycomorus $L$. (moraceae)" Best Journal 3(2), pp. 18-25, 2006

[9]. G. Heinike, "Tribochemistry", Academie-Verlag, Berlin. Acta Polymerica. 36(7), pp. 400-401, 1984

[10]. M. A. Kurawa and S. G. Yammama, "Solid state synthesis, characterization and antimicrobial study of 4,4'-bipyridine copper (II) complexes. ChemSearch Journal 5(2), pp. $39-45,2014$

[11]. M. A. Kurwa. and S. G. Yammama, "Solid state synthesis, characterisation and biological activity of 4,4'-bipyridiniumtetrachloronickelate (II) and 4,4'bipyridine dichloronickel (II) complexes", ChemSearch Journal, 5(1), pp. 59 - 65, 2014

[12]. H.D. Lewis, "et al, "Protective effect of aspirin against acute myocardial infection and death in men with unstable angina. results of the veterans administration cooperative study", NEng. J. of Med., 309(7), pp. 396-403, 1983

[13]. F.B. Livingstone, "Frequencies of hemoglobin variant: Hialassemia, the glucose-6- phosphate dehydrogenase deficiency, G6PD variants and ovalocytosis in human population", Oxford University Press, New York, 1985 , pp. 526

[14]. J.A. Obaleye, and A. Lawal, "Synthesis, characterization and antibacterial activity of aspirin and paracetamol metal complexes", J. of BIOKEMISTRI, 19(1), pp. 9-15, 2007

[15]. I. A. Odesina, "Essential chemistry for senior secondary schools," $2^{\text {nd }}$ Ed., TONAD Publishers Limited, Ibafo, Ogun state, pp. 465-466, 2008

[16]. P.V. Rao, K. Ashwini and S. Ammani, "Synthesis and characterization of transition metal complexes derived from some biologically active furoic acid hydrazones" Bull.Chem.Soc. Ethiopia, Vol. 21(1), pp. 63-73, 2007
[17]. M.S. Refat, S.A. El-korashy and M.A. Hussien, "Ligational, spectroscopic (infrared and electronic) and thermal studies on the Mn(II), Co(II), Fe(II) and $\mathrm{Cu}$ (II) complexes with analgesis drugs", Journal of Canadian Chemical Transactions, Vol. 2, Issue 1, pp. 24-35, 2014

[18]. B. S. Sekhon, and L. Gandhi, "Synthesis and Characterization of Metal Complexes of Some Antimicrobial Drugs, Intl. J. of Chemtech Research, 2(1), pp. 286-288, 2010

[19]. A.C. Tella, "Friendly synthesis of metal complexes of antimicrobial drugs", report from Cent. for supramolecular chemistry research", Uni. of Capetown, South Africa, 2011, pp.1-4

[20]. A.C. Tella, U.B. Eke and S.O. Owalude, "Solvent free mechanochemical synthesis and X-ray studies of $\mathrm{Cu}$ (II) and $\mathrm{Ni}$ (II) complexes of 5-(3,4,5trimethoxybenzyl)pyrimidine-2,4-diamine (Trimethoprim) in a ball-mill", J. of Saudi Chem. Soc. Elsevier, 20, pp. S376-S381, 2016

[21]. Y. Vibhute, A. Vibhute, A. S. Zangade and S. Mokle, "An Efficient and Operationally Simple Synthesis of Some New Chalcones by Using Grinding Technique”, Chem. Sci. J., Vol. 2011(13), pp. 1-6, 2011

[22]. M. Yusha'u and F. U. Salisu, "Inhibition activity of detarium microcarpum extract on Some clinical bacterial isolates. Biol. and Env. Sci. J. for the Tropics, 8(4), pp. 113-117, 2011 